\title{
Sadržaj teških metala i metaloida u vodi za piće u Unsko-sanskoj županiji Federacije Bosne i Hercegovine
}

\author{
E. Pehlić, ${ }^{a *}$ N. Ljubijankić, ${ }^{b}$ H. Jukić, ${ }^{a}$ A. Šapčaninc i H. Nanića \\ a Fakultet zdravstvenih studija, Univerzitet u Bihaću, Hrvatskog trolista 4, 77000 Bihać, BiH \\ b Prirodno-matematički fakultet, Odsjek za kemiju, Univerzitet u Sarajevu, Zmaja od Bosne 33-35, \\ 71000 Sarajevo, BiH \\ cFarmaceutski fakultet, Univerzitet u Sarajevu, Zmaja od Bosne 8, 71000 Sarajevo, BiH
}

DOI: 10.15255/KUI.2018.036

$\mathrm{KUI}-7 / 2019$

Izvorni znanstveni rad

Prispjelo 3. srpnja, 2018.

Prihvaćeno 2. listopada, 2018.

Ovo djelo je dano na korištenje pod Creative Commons Attribution 4.0 International License

\begin{abstract}
Sažetak
Unsko-sanska županija bogata je prirodnom izvorskom vodom, kojom se opskrbljuje stanovništvo. Po prvi put je ispitana procjena kakvoće toksičnih i esencijalnih teških metala i metaloida u vodi za piće iz više izvorišta u osam općina i to: Bihaću, Cazinu, Bosanskoj Krupi, Bužimu, Velikoj Kladuši, Bosanskom Petrovcu, Sanskom Mostu i Ključu. U svibnju 2016. godine iz svake općine analizirano je po tri uzorka vode (ukupno 24). Mjerene su koncentracije arsena, olova, kadmija, kroma, nikla, kobalta, molibdena, fosfora, cinka i bakra. U pet uzoraka vode uočene su povećane koncentracije za $\mathrm{Ni}\left(\mathrm{do} 20 \mathrm{\mu g} \mathrm{dm}^{-3}\right)$ i Cr $\left(\mathrm{do} 50 \mu \mathrm{g} \mathrm{dm}^{-3}\right)$ i smatraju se prirodnim podrijetlom. Međutim, u većem broju uzoraka (osam) koncentracije As su odstupale od dozvoljenih (do $10 \mu \mathrm{g} \mathrm{dm}^{-3}$ ), s maksimumom od 14,05 $\mu \mathrm{g} \mathrm{dm}^{-3}$ i vjerojatno su od samog sastava zemljišta, ali i antropogenih izvora zbog postojanja odlagališta otpada u široj regiji izvorišta. Vrijednosti koncentracija ostalih elemenata Cd, Pb, Co, Cu, P, Mo i Zn bile su u granicama maksimalno dozvoljenih propisanih Pravilnicima u BiH, Direktivom o vodi za ljudsku potrošnju 98/83/EC, kao i smjernicama Svjetske zdravstvene organizacije (WHO). Sadržaj teških metala i metaloida u vodi za piće na području Unsko-sanske županije, osim za As ne predstavljaju opasnost za zdravlje ljudi.
\end{abstract}

\section{Ključne riječi}

Teški metali, voda za piće, Unsko-sanska županija

\section{Uvod}

Bosna i Hercegovina, a posebno Unsko-sanska županija raspolaže velikim količinama kvalitetne izvorske vode i voda je najznačajniji prirodni resurs na području ove županije. Teški metali zbog industrijskog onečišćenja i antropogenih čimbenika, mogu se naći u vodi za piće, ali dolaze i od samog zemljišta jer su sastavni dio zemljine kore. Međutim, u posljednje vrijeme pojavila se fito-remedijacija kao obećavajuća ekoremedijacijska tehnologija za sanaciju tla onečišćenim elementima. ${ }^{1}$ Distribucijom vode za piće od izvorišta do korisnika, koncentracije metala mogu se povećati tijekom noći prilikom skladištenja vode u cijevima. ${ }^{2}$ Teški metali mogu uzrokovati ozbiljne zdravstvene probleme $^{3}$ i tegobe, od neuropsihijatrijskih poremećaja kao što su agresivno ponašanje, gubitak pamćenja, depresija, razdražljivost, umor, do neplodnosti, gihta, hipertenzije i glavobolje. ${ }^{4}$ Sve površinske vode na području županije pripadaju vodnom području rijeke Save (Crnomorski sliv), odnosno podslivu rijeke Une s Koranom i Glinom. Rijeka Una je najveća rijeka na području županije, a specifičnost područja podsliva rijeke Une je utjecaj krša, koja se manifestira u ne tako znatno izraženoj hidrografiji, već postojanju znatnog broja krških vrela (vrelo Klokot, Dabarsko vrelo, Zdene, Sanice, kao i sama vrela Une i Sane). ${ }^{5}$ Podzemne vode se u vidu kraških izvora i vrela javljaju po obodima planinskih masiva Plješivice, Grmeča i dr. Na području Un-

*Autor za dopisivanje: Prof. dr. Ekrem Pehlić, izvanredni profesor e-pošta: pehlic_ekrem@yahoo.com sko-sanske županije podzemnim vodama osobito su bogate općine: Bihać, Cazin, Velika Kladuša, Bosanska Krupa i Ključ. Radi uvida u kvalitetu vode za piće, cilj istraživanja je odrediti koncentracije toksičnih i esencijalnih teških metala i metaloida u vodi za piće i to $\mathrm{As}, \mathrm{Pb}, \mathrm{Cd}, \mathrm{Cr}, \mathrm{Ni}, \mathrm{Co}$, Mo, P, Zn i Cu u osam općina Unsko-sanske županije.

\section{Eksperimentalni dio}

\subsection{Uzorkovanje}

Analizirani uzorci vode uzeti su u mjesecu svibnju 2016. iz osam općina Unsko-sanske županije, Federacije Bosne i Hercegovine i to: Bihaća, Cazina, Bosanske Krupe, Bužima, Velike Kladuše, Bosanskog Petrovca, Sanskog Mosta i Ključa. Iz svake općine uzeta su po tri uzorka iz različitih distribucijskih sustava kojima se opskrbljuje stanovništvo, kako bi se odredile koncentracije teških metala i metaloida. Ukupno je uzeto 24 uzorka, u skladu s propisanim standardima za uzimanje uzoraka ${ }^{6}$ te uputama za postupak uzimanja uzoraka. ${ }^{7}$ Pakiranje, prijevoz i čuvanje uzoraka provodilo se na način kojim se čuva jednaka kvaliteta uzoraka od njegovog uzimanja do početka postupka analize. ${ }^{8}$

\subsection{Mjesta uzorkovanja}

Uzorci vode uzimani su na većim (glavnim) izvorištima na području Unsko-sanske županije. Svaka općina/grad ima 
više izvorišta s kojim se stanovništvo opskrbljuje pitkom vodom. U istraživanju su analizirana izvorišta (tablica 1) kojima se opskrbljuje najveći dio stanovništva, kojima upravljaju javna poduzeća "Vodovod" na razini općina/grada.

Tablica 1 - Naziv izvorišta i općina uzorkovanja

Table 1 - Name of source and sampling municipality

\begin{tabular}{|c|c|c|}
\hline $\begin{array}{c}\text { Broj uzorka } \\
\text { Sample number }\end{array}$ & $\begin{array}{l}\text { Općina uzorkovanja } \\
\text { Sampling municipality }\end{array}$ & $\begin{array}{l}\text { Naziv izvorišta } \\
\text { Source name }\end{array}$ \\
\hline 1. & Sanski Most & Zdena \\
\hline 2. & Ključ & Okašnica \\
\hline 3. & Bosanski Petrovac & Sanica \\
\hline 4. & Velika Kladuša & Kvrkulja \\
\hline 5. & Bužim & Musići \\
\hline 6. & Bihać & Privilica \\
\hline 7. & Cazin & Stovrela \\
\hline 8. & Bosanska Krupa & Ada \\
\hline 9. & Sanski Most & Dabar \\
\hline 10. & Ključ & Bušotina \\
\hline 11. & Bosanski Petrovac & Smoljani \\
\hline 12. & Velika Kladuša & Šumatac \\
\hline 13. & Bužim & Pivnice \\
\hline 14. & Bihać & Klokot \\
\hline 15. & Cazin & Vignjevići \\
\hline 16. & Bosanska Krupa & Luke \\
\hline 17. & Sanski Most & Zdena \\
\hline 18. & Ključ & Okašnica \\
\hline 19. & Bosanski Petrovac & Sanica \\
\hline 20. & Velika Kladuša & Kvrkulja \\
\hline 21. & Bužim & Musići \\
\hline 22. & Bihać & Privilica \\
\hline 23. & Cazin & Stovrela \\
\hline 24. & Bosanska Krupa & Ada \\
\hline
\end{tabular}

\subsection{Pripreme uzoraka}

Uzorci vode zakiseljeni su nitratnom kiselinom tako da se $\mathrm{pH}$ podesi na vrijednost od 2. Prije mjerenja uzorci su filtrirani kroz filtarski papir od 0,45 $\mu \mathrm{m}$ (Filtres Fioroni). Za kalibraciju instrumenta primijenjen je multistandard AAS Fluka koncentracije $1000 \mathrm{\mu g} \mathrm{dm}^{-3}$ od kojeg je razrjeđenjem napravljena serija standarda potrebnih za kalibraciju i određivanje koncentracija u uzorcima vode. Koncentra- cije teških metala mjerene su atomskom apsorpcijskom spektroskopijom (AAS) na instrumentu Shimadzu 6800.

\section{Rezultati i rasprava}

Sadržaj teških metala u vodi za piće iz osam općina Unsko-sanske županije prikazani su u tablici 2. U tablici su prikazane i vrijednosti maksimalno dozvoljenih koncentracija (MDK), prema regulativi Bosne i Hercegovine ${ }^{9,10} \mathrm{i}$ danim smjernicama o kvaliteti vode za piće Svjetske zdravstvene organizacije $(\mathrm{WHO})^{11}$ kao i Direktive EU 98/83/EC. ${ }^{12}$

Povišene koncentracije teških metali u vodi za piće prijetnja su ljudskom zdravlju jer se teški metali mogu bioakumulirati u ljudskom tijelu (lipidima i gastrointestinalnom sustavu). ${ }^{13}$ Kao toksični metal, koncentracije Cd u svim uzorcima su ispod maksimalno dopuštenih od $5 \mu \mathrm{g} \mathrm{dm}{ }^{-3}$, koje su propisane Pravilnikom o maksimalno dopuštenim koncentracijama u BiH. Kadmij se akumulira ponajprije u bubrezima i ima dug biološki poluživot kod ljudi od 10 do 35 godina. IARC je klasificirao kadmij i kadmijeve spojeve u skupini 2A (vjerojatno karcinogen za ljude). Međutim, ne postoji dokaz karcinogenosti oralnim putem i nema jasnih dokaza za genotoksičnost kadmija.

Bubreg je glavni ciljni organ za toksičnost kadmija. ${ }^{14}$ Koncentracija Pb u uzorku 10 (Bušotina) u općini Ključ bila je neznatno iznad MDK prema regulativi $\mathrm{BiH}$, s koncentracijom od 10,98 $\mathrm{ug} \mathrm{dm}^{-3}$. Sve ostale koncentracije Pb bile su ispod maksimalno dopuštenih. Studija utjecaja olova na zdravlje čovjeka otkrila je bitan nalaz u vezi s rakom, a to je značajan višak malignih neoplazmi probavnog trakta. ${ }^{15}$ Sadržaj As u uzorcima 2, 6, 7, 11, 12, 14, 16 i 22 iznad su maksimalno dopuštenih, a najveća koncentracija je u uzorku 16 (Luke) u općini Bosanska Krupa od 14,05 $\mathrm{gg} \mathrm{dm}^{-3}$. Te povišene koncentracije As koje su iznad maksimalno dopuštenih od $10 \mu \mathrm{g} \mathrm{dm}{ }^{-3}$ vjerojatno potiču od antropogenih izvora, a mogu biti i od samog sastava zemljišta. Takve vrijednosti As mogu utjecati na djetetovu inteligenciju i rast. ${ }^{16}$ Rezultati IQ-a djece u grupi povišenog As u krvi bili su najniži između četiri skupine koje su bile izložene visokoj koncentraciji As. Ujedno može doći do slabljenja imunološkog sustava odnosno pada imuniteta kod djece. ${ }^{17}$ Također, povišene koncentracije arsena u vodi za piće povezane su s povećanim rizikom od raka mokraćnog mjehura i bubrega. ${ }^{18,19}$

Koncentracija Co u uzorcima 11, 12 i 22 bila je ispod granice detekcije primijenjene metode, a najviša u uzorku 21 od 63,90 $\mathrm{gg} \mathrm{dm}^{-3}$. Za Co kao esencijalni element nisu propisane vrijednosti maksimalne koncentracije u vodi za piće od strane WHO-a, niti pravilnicima $\mathrm{u} \mathrm{BiH}$. Visoke koncentracije spojeva Co u vodi mogu negativno utjecati na zdravlje ljudi ${ }^{20}$. Najviši sadržaj Ni je u uzorku 24 s koncentracijom 31,2 $\mathrm{gg} \mathrm{dm}^{-3}$, što je više od propisane gornje granične vrijednosti od $20 \mu \mathrm{g} \mathrm{dm^{-3 }}$. Također, uzorci broj 7, 11, 12 i 17 imali su nešto više vrijednosti $\mathrm{Ni}$ od propisanih, ${ }^{21}$ dok su ostali uzorci imali daleko manje koncentracije. Nikal, ako dospije u organizam, može prijeći placentarnu barijeru, čime može izravno utjecati na prenatalni razvoj embrija. Zabilježena su fetalna smrt i malformacije nakon ubrizgavanja različite vrste nikalnih 
Tablica 2 - Vrijednosti maksimalnih koncentracija teških metala i metaloida u vodi za piće

Table 2 - Maximum concentration values of heavy metals and metalloids in drinking water

\begin{tabular}{|c|c|c|c|c|c|c|c|c|c|c|}
\hline \multirow{2}{*}{$\begin{array}{c}\text { Broj uzorka } \\
\text { Sample } \\
\text { number }\end{array}$} & \multicolumn{10}{|c|}{$\begin{array}{l}\text { Koncentracija } / \mu g \mathrm{dm}^{-3} \\
\text { Concentration } / \mu \mathrm{gdm}\end{array}$} \\
\hline & $\mathrm{Cd}$ & $\mathrm{Pb}$ & As & Co & $\mathrm{Ni}$ & $\mathrm{Cu}$ & $\mathrm{P}$ & Mo & $\mathrm{Zn}$ & $\mathrm{Cr}$ \\
\hline & ${ }^{*} 5,00$ & ${ }^{*} 10,00$ & ${ }^{*} 10,00$ & - & ${ }^{*} 20,00$ & ${ }^{*} 2000$ & ${ }^{*} 300$ & ${ }^{* *} 70,00$ & ${ }^{* *} 3000$ & ${ }^{* * *} 50,00$ \\
\hline 1. & 1,85 & 7,95 & 8,02 & 5,30 & 16,40 & $1.367,9$ & 150,0 & 35,70 & 44,60 & 41,60 \\
\hline 2. & 1,28 & 4,24 & 10,54 & 21,30 & 1,70 & 361,0 & 160,0 & 40,80 & 55,50 & 25,00 \\
\hline 3. & 1,15 & 7,01 & 8,18 & 47,90 & 7,40 & 889,6 & 130,0 & 20,00 & 165,0 & 54,90 \\
\hline 4. & 2,49 & 4,95 & 7,32 & 8,00 & 5,10 & 445,6 & 240,0 & 28,70 & 12,90 & 21,60 \\
\hline 5. & 0,95 & 2,86 & 4,80 & 49,30 & 15,30 & 240,8 & 160,0 & 54,50 & 31,60 & 61,60 \\
\hline 6. & 2,64 & 4,91 & 10,75 & 28,00 & 17,60 & 189,2 & 120,0 & 32,30 & 8,60 & 38,30 \\
\hline 7. & 2,47 & 2,06 & 13,68 & 21,30 & 22,10 & 451,9 & 200,0 & 35,40 & 15,60 & 25,00 \\
\hline 8. & 1,31 & 8,56 & 5,50 & 34,60 & 0,60 & 806,9 & 120,0 & 15,60 & 10,40 & 71,60 \\
\hline 9. & 1,01 & 6,29 & 7,44 & 5,30 & 7,40 & 281,5 & 160,0 & 35,20 & 2,60 & 35,00 \\
\hline 10. & 2,32 & 10,98 & 2,73 & 37,30 & 18,70 & 382,6 & 130,0 & 12,00 & 60,20 & 18,30 \\
\hline 11. & 0,89 & 6,11 & 13,31 & $<0,01$ & 25,50 & 592,5 & 160,0 & 3,00 & 20,00 & 8,30 \\
\hline 12. & 2,30 & 2,40 & 11,49 & $<0,01$ & 28,90 & 471,0 & 140,0 & 24,30 & 60,00 & 54,90 \\
\hline 13. & 1,05 & 8,47 & $<0,01$ & 32,00 & 11,90 & 806,9 & 160,0 & 30,40 & 10,00 & 31,60 \\
\hline 14. & 0,87 & 7,45 & 11,03 & 47,90 & 15,30 & $1.018,0$ & 130,0 & 37,40 & 4,00 & 58,30 \\
\hline 15. & 2,01 & 9,59 & 7,73 & 26,60 & $<0,01$ & 392,8 & 140,0 & 19,70 & 520,0 & 15,00 \\
\hline 16. & 1,07 & 3,89 & 14,05 & 43,90 & 6,20 & 472,3 & 120,0 & 27,00 & 540,0 & 11,10 \\
\hline 17. & 2,63 & 5,88 & 7,23 & 20,00 & 27,80 & 885,7 & 140,0 & 6,70 & 870,0 & 61,10 \\
\hline 18. & 0,78 & 1,72 & 1,95 & 34,60 & 5,10 & 532,7 & 140,0 & 22,10 & 700,0 & 41,10 \\
\hline 19. & 2,64 & 2,38 & $<0,01$ & 49,30 & 4,00 & 497,1 & 120,0 & 44,10 & 770,0 & 38,30 \\
\hline 20. & 1,36 & 8,41 & 3,77 & 29,30 & 6,20 & $1.011,0$ & 190,0 & 3,50 & 1.046 .5 & 28,30 \\
\hline 21. & 0,83 & 5,03 & 8,85 & 63,90 & $<0,01$ & 274,5 & 150,0 & 22,40 & 570,0 & 64,90 \\
\hline 22. & 1,36 & 9,86 & 13,59 & $<0,01$ & 9,60 & 455,7 & 110,0 & 3,70 & 840,0 & 18,30 \\
\hline 23. & 1,48 & 6,32 & 1,70 & 14,60 & 8,50 & $1.056,8$ & 190,0 & 11,50 & 500,0 & 21,60 \\
\hline 24. & 2,01 & 7,59 & 6,28 & 51,90 & 31,20 & $1.021,2$ & 130,0 & 25,00 & 370,0 & 8,30 \\
\hline
\end{tabular}

${ }^{*}$ Maksimalno dopuštene koncentracije Pravilnik $\mathrm{BiH} / \mu \mathrm{g} \mathrm{dm}{ }^{-3}$

${ }^{* *}$ Maksimalno dopuštene koncentracije $\mathrm{WHO} / \mathrm{\mu g} \mathrm{dm}^{-3}$

${ }^{* * *}$ Maksimalno dopuštene koncentracije Direktiva EU 98/83/EC/ $\mu g \mathrm{dm}^{-3}$

spojeva u pokusnim životinjama. ${ }^{22}$ Sadržaj $\mathrm{Cu}$ je ispod maksimalno dopuštenih vrijednosti od $2000 \mu \mathrm{g} \mathrm{dm}^{-3}$, kao i koncentracije ukupnog fosfora $(\mathrm{P})$, te su u referentnim vrijednostima. Molibden kao esencijalni element u tragovima veoma je bitan za ljudsko zdravlje jer ulazi u strukturu mnogih enzima kao Mo-kofaktor. Nedostatak molibdena u ljudskom organizmu povezan je s neurološkim abnormalnostima, pa čak i smrću u ranom djetinjstvu, ${ }^{23,24}$ dok kronična izloženost Mo uzrokuje slab apetit, anoreksiju, umor, tremor, poremećaj u radu jetara, bolove u zglobovima i osteoporozu. ${ }^{25}$ Sadržaj Mo u uzorcima vodi za piće su u granicama koje je propisao $\mathrm{WHO}^{26}$ Koncentracije $\mathrm{Zn}$ su ispod MDK od $3000 \mu \mathrm{g} \mathrm{dm}^{-3}$ prema $\mathrm{WHO}-\mathrm{u}^{27}$ dok Direktivom EU98/83/EC o kvaliteti vode namijenjene ljudskoj potrošnji i Pravilnicima u BiH nisu regulirane maksimalne koncentracije za Zn u prirodnoj i izvorskoj vodi za piće. Najviša izmjerena koncentracija $\mathrm{Cr}$ je u izvorištu Ada u općini Bosanska Krupa 71,60 $\mu \mathrm{g} \mathrm{dm}^{-3}$, što prelazi dopuštenu vrijednost od $50 \mu \mathrm{g} \mathrm{dm}^{-3}$ propisanu Direktivom EU98/83/ EC o kvaliteti vode namijenjene ljudskoj potrošnji. Također, koncentracije Cr u sedam uzoraka: 3, 5, 8, 12, 14, 17 i 21 bile su nešto iznad granične vrijednosti. Krom je teški metal, koji se nalazi u različitim oksidacijskim stanjima, u rasponu od -2 do +6 , a najstabilniji oblici su trovalentni i heksavalentni krom. Primarne zdravstvene opasnosti uzrokovane kromom su bronhijalna astma, plućni i nosni čirevi i rak, alergije kože, reproduktivni i razvojni problemi. Kada se uzme u suvišku, može uzrokovati i smrt. ${ }^{28}$ 


\section{Zaključak}

Od analiziranih 240 uzoraka, sedam uzoraka vode za piće u Unsko-sanskoj županiji imali su koncentracije metala i metaloida ispod granice detekcije primijenjene metode. Kod nekih metala bile su povišene vrijednosti koncentracija i to $\mathrm{Ni}$ i $\mathrm{Cr}$, ali nešto više koncentracije As u pojedinim uzorcima iznad su propisanih Pravilnikom u BiH. Ne postoji povezanost između koncentracija analiziranih metala i metalioda s općinom uzorkovanja vode. Sadržaj ostalih teških metala u vodi za piće nije prelazio dopuštene vrijednosti regulirane Pravilnikom o prirodnim mineralnim i prirodnim izvorskim vodama u $\mathrm{BiH}$, Pravilnikom o zdravstvenoj ispravnosti vode za piće u BiH i Direktivom o kvaliteti vode namijenjene ljudskoj potrošnji 98/83/EC i smjernicama WHO-a.

\section{ZAHVALA}

Istraživanja su realizirana u okviru znanstveno-istraživačkog projekta koji je financiralo Federalno Ministarstvo obrazovanja i nauke BiH broj: 05-39-3861/15.

\section{Popis kratica List of abbreviations}

$\begin{array}{ll}\text { AAS } & \text { - atomska apsorpcijska spektroskopija } \\ & - \text { atomic absorption spectroscopy } \\ \text { IARC } & \text { - Međunarodna agencija za istraživanje raka } \\ & - \text { International Agency for Research on Cancer } \\ \text { MKD } & \text { - maksimalno dopuštena koncentracija } \\ & \text { - maximum permissible concentration } \\ \text { IQ } & \text { - kvocijent inteligencije } \\ & \text { - intelligence quotient } \\ \text { WHO } & - \text { Svjetska zdravstvena organizacija } \\ & - \text { World Health Organization }\end{array}$

\section{Literatura}

\section{References}

1. O. V. Singh, S. Labana, G. Pandey, R. Budhiraja, R. K. Jain, Phytoremediation: an overview of metallic ion decontamination from soil, Appl. Microbiol. Biotechnol. 61 (2003) 405-412, doi: https://doi.org/10.1007/s00253-003-1244-4.

2. I. A. Alam, M. Sadiq, Metal contamination of drinking water from corrosion of distribution pipes, Environ. Pollut. 57 (1989) 167-178, doi: https://doi.org/10.1016/02697491(89)90008-0.

3. H. S. Bawaskar, P. H. Bawaskar, Chronic renal failure associated with heavymetal contamination of drinking water: A clinical report from a small village in Maharashtra, Clin. Toxicol. 48 (7) (2010) 768-769, doi: https://doi.org/10.3109/15563 650.2010.49776.

4. M. Jaishankar, T. Tseten, N. Anbalagan, B. B. Mathew, K. N. Beeregowda, Toxicity, Mechanism and health effects of some heavy metals, Interdiscip. Toxicol. 7 (2) (2014) 60-72, doi: https://doi.org/10.2478\%2Fintox-2014-00093.

5. Plan zaštite okoliša Unsko-sanskog kantona 2014-2019, "Una Consulting" - Resursni centar za vode i okoliš, 2014. str. 29-32.
6. BAS ISO 5667-5:2007, Water quality - Sampling - Part 5: Guidance on sampling of drinking water from treatment works and piped distribution systems.

7. BAS EN ISO 5667-1:2008, Water quality - Sampling - Part 1: Guidance on the design of sampling programmes and sampling techniques.

8. BAS EN ISO 5667-3:2005, Water quality - Sampling - Part 3: Guidance on the preservation and handling of water samples.

9. Pravilnik o prirodnim mineralnim i prirodnim izvorskim vodama u BiH (Službeni glasnik BiH, br. 26/10).

10. Pravilnik o zdravstvenoj ispravnosti vode za piće u BiH (Službeni glasnik $\mathrm{BiH}$, br. 40/10).

11. World Health Organization, Guidelines for drinking water quality, fourth edition incorporating the first addendum, 2017., str. 394, 433.

12. Council Directive $98 / 83 /$ EC, The quality of water intended for human consumption, 1998, L 330/32.

13. M. Araya, M. Olivares, F. Pizarro, Gastrointestinal symptoms and blood indicators of copper load in apparently healthy adults undergoing controlled copper exposure, Am. J. Clin. Nutr. 77 (3) (2003) 646-650, doi: https://doi.org/10.1093/ ajcn/77.3.646.

14. S. Chowdhury, M.A. Jafar Mazumder, O. Al-Attas, T. Husain, Heavy metals in drinking water: Occurrences, implications, and future needs in developing countries, Sci. Total Environ. 569-570 (2016) 476-488, doi: https://doi.org/10.1016/j.scitotenv.2016.06.166.

15. D. Malcolm, H. Barnett, A mortality study of lead workers: 1925-76. Br. J Ind Med 39 (4) (1982) 404-410.

16. S. X. Wang, Z. H. Wang, X. T. Cheng, J. Li, Z. P. Sang, X. D. Zhang, L. L. Han, X. Y. Qiao, Z. M. Wu, Z. Q. Wang, Arsenic and fluoride exposure in drinking water: children's IQ and growth in Shanyin county, Shanxi province, China. Environ. Health. Perspect. 115 (4) (2007) 643-647, doi: https://doi. org/10.1289/ehp.9270.

17. R. Baastrup, M. Sorensen, T. Balstrom, K. Frederiksen, C. L. Larsen, A. Tjonneland, K. Overvad, O. Raaschou-Nielsen, Arsenic in drinking-water and risk for cancer in Denmark. Environ. Health Perspect. 116 (2008) 231-237, doi: https:// doi.org/10.1289/ehp.10623.

18. L. Parker, P. Brown, T. J. Dummer, Arsenic in drinking water and urinary tract cancers: a systematic review of 30 years of epidemiological evidence, Environ. Health 13 (44) (2014), doi: https://doi.org/10.1186/1476-069X-13-44.

19. E. P. Christoforidou, E. Riza, S. N. Kales, K. Hadjistavrou, M. Stoltidi, A. N. Kastania A. Linos, Bladder cancer and arsenic through drinking water: a systematic review of epidemiologic evidence, J. Environ. Sci. Health A 48 (14) (2013) 1764-1775, doi: https://doi.org/10.1080/10934529.2013.8 23329.

20. The International Agency for Research on Cancer (IARC), Chlorinated drinking-water; chlorination byproducts; some other halogenated compounds; cobalt and cobalt compounds. Lyon, International Agency for Research on Cancer (IARC Monographs on the Evaluation of Carcinogenic Risks to Humans, Vol. 52, 1991., str. 72-77.

21. Environmental Health Criteria, Nickel. WHO, Geneva, 1991., 108, ISBN 924157108 X.

22. Nickel and nickel compounds. In: Chromium, nickel and welding. Lyon, International Agency for Research on Cancer, (IARC Monographs on the Evaluation of Carcinogenic Risks to Humans), Vol. 49, 1990., str. 318-400.

23. Food and Nutrition Board, Institute of Medicine, Molybde- 
num. In: Dietary Reference Intakes for Vitamin A, Vitamin K, Arsenic, Boron, Chromium, Copper, lodine, Iron, Manganese, Molybdenum, Nickel, Silicon, Vanadium, and Zinc. National Academy Press, Washington DC, USA, Chapter 11, 2001., str. 420-441.

24. B. Wahl, D. Reichmann, D. Niks, N. Krompholz, A. Havemeyer, B Clement, T. Messerschmidt, M. Rothkegel, H. Biester, R. Hille, R. R. Mendel, F. Bittner, Biochemical and spectroscopic characterization of the human mitochondrial amidoxime reducing components hmARC- 1 and hmARC-2 suggests the existence of a new molybdenum enzyme family in eukaryotes, J. Biol. Chem. 26 (2010) 37847-37859, doi: https:// doi.org/10.1074/jbc.M110.169532.
25. Molybdenum in Drinking Water: Background Document for Development of WHO Guidelines for Drinking-water Quality (WHO/SDE/WSH/03.04/11/Rev/1), World Health Organization, 2011., str. 4-5.

26. Molybdenum in Drinking-water Background document for development of WHO Guidelines for Drinking-water Quality, World Health Organization, 2011., str. 394-395.

27. Guidelines for drinking-water quality, Health criteria and other supporting information. World Health Organization, Vol. 2, 1996, str. 382-385.

28. K. Shekhawat, S. Chatterjee, B. Joshi, Chromium Toxicity and its Health Hazards, Int. J. Adv Res. 7 (3) (2015) 167-172.

\section{SUMMARY}

Content of Heavy Metals and Metalloids in Drinking Water in the
Una-Sana Canton of the Federation of Bosnia and Herzegovina
Ekrem Pehlić, ${ }^{*}$ Nevzeta Ljubijankić, Huska Jukić, a Aida Šapčanin, and Husein Nanića

The Una-Sana Canton is rich in natural spring water that supplies the population. Performed for the first time was a quality assessment of toxic and essential heavy metals and metalloids in drinking water from several sources in eight municipalities: Bihac, Cazin, Bosanska Krupa, Buzim, Velika Kladusa, Bosanski Petrovac, Sanski Most, and Kljuc. In May 2016, three samples were taken from each municipality (total 24). The concentrations of arsenic, lead, cadmium, chromium, nickel, cobalt, molybdenum, phosphorus, zinc, and copper were measured. In a small number of water samples, slightly increased concentrations of $\mathrm{Ni}$ (up to $20 \mu \mathrm{g} \mathrm{dm}^{-3}$ ) and $\mathrm{Cr}$ (up to $50 \mu \mathrm{g} \mathrm{dm}^{-3}$ ) were found, and considered to be of natural origin. However, in the majority of samples, the As concentrations differed from the allowed concentration (up to $10 \mu \mathrm{g} \mathrm{dm}^{-3}$ ), with a maximum of $14.05 \mu \mathrm{g} \mathrm{dm}^{-3}$, which probably originates from the very composition of the soil, but also from anthropogenic sources due to the existence of a landfill in the wider region of the source. The concentrations of other elements, $\mathrm{Cd}, \mathrm{Pb}, \mathrm{Co}, \mathrm{Cu}, \mathrm{P}, \mathrm{Mo}$, and $\mathrm{Zn}$ were within the maximum permissible limits prescribed by the Regulations of B\&H, the EU Drinking Water Directive 98/83/EC, as well as the WHO guidelines. Except for As, the content of heavy metals and metalloids in the drinking water of Una-Sana Canton is not a danger to human health.

\section{Keywords}

Heavy metals, drinking water, Una-Sana canton

a Faculty of Health Sciences, University of Bihac, Hrvatskog trolista 4, 77000 Bihac, B\&H

${ }^{\mathrm{b}}$ Faculty of Science, Department of Chemistry, University of Sarajevo, Zmaja od Bosne 33-35, 71000 Sarajevo, B\&H

' Faculty of Pharmacy, University of Sarajevo, Zmaja od Bosne 8, 71000 Sarajevo, B\&H

\author{
Original scientific paper \\ Received July 3, 2018 \\ Accepted October 2, 2018
}

